\title{
ФИНАНСОВОЕ ОЗДОРОВЛЕНИЕ ЭКОНОМИЧЕСКИ НЕСОСТОЯТЕЛЬНЫХ ПРЕДПРИЯТИЙ В УЗБЕКИСТАНЕ
}

\author{
Мамараимов Илхом Ражаббаевич \\ Академия Государственного управления при Президенте Республики Узбекистан, \\ Ташкент, Узбекистан
}

DOI: https://doi.org/10.31435/rsglobal_ijite/30082018/6112

\begin{abstract}
ARTICLE INFO
Received 08 June 2018

Accepted 17 August 2018

Published 30 August 2018

ABSTRACT

This article analyzes the current state of financial recovery of economically insolvent enterprises. Proposals and recommendations were developed to address the identified problems.
\end{abstract}

\section{KEYWORDS}

Enterprise,

economically insolvent

enterprise,

investment,

investment loan,

commercial banks,

financial rehabilitation.

Citation: Мамараимов Илхом Ражаббаевич. (2018) Finansovoe Ozdorovlenie Ekonomicheski Nesostoyatelnih Predpriyatii $\mathrm{v}$ Uzbekistane. International Journal of Innovative Technologies in Economy. 7(19). doi: 10.31435/rsglobal_ijite/30082018/6112

Copyright: (C) 2018 Мамараимов Илхом Ражаббаевич. This is an open-access article distributed under the terms of the Creative Commons Attribution License (CC BY). The use, distribution or reproduction in other forums is permitted, provided the original author(s) or licensor are credited and that the original publication in this journal is cited, in accordance with accepted academic practice. No use, distribution or reproduction is permitted which does not comply with these terms.

Введение. Среднесрочная перспективная стратегия Узбекистана направлена на расширение реального сектора экономики реабилитация и увеличение его инвестиционной активности. В частности, коммерческие банки Узбекистана активно поддерживают модернизацию реального сектора экономики, создание новых рабочих мест за свой счет. В частности, нетрадиционная практика инвестиционной деятельности банков показала эффективность нашего нетрадиционного подхода к переводу экономически несостоятельных предприятий на баланс банков и их восстановление. Эффективность этой практики привела к сохранению этих предприятий в качестве субъектов бизнеса и сохранению рабочих мест. Экономически несостоятельные предприятия несут ответственность за восстановление конкурентоспособной продукции и повышение финансовой устойчивости этих предприятий. В этой статье мы рассмотрим направления экономически эффективного решения этой проблемы.

Ученые-экономисты изучили свой опыт в развивающихся странах путем финансовой реабилитации экономически несостоятельных предприятий. Для успешной разработки эффективных методов регулирования проблем несостоятельности необходим финансово-экономический анализ применяемых в этой сфере подходов в развитых странах, таких как Англия, Франция и Германия, где определенные меры и процедуры по преодолению банкротства складывались столетиями. Это необходимо также и с точки зрения регулирования процедуры банкротства.

В зарубежных странах банки рассматривались как инвестиции в балансы банков или в качестве обеспечения, и они рассматривались как проблема управления предприятиями на балансе. Продажа экономически неплатежеспособных предприятий для инвесторов рассматривается как способ избавиться от ненадежных активов в банках. 
В частности, Н. Бубхардт, Н. Стефан [1], Вахабов, Жумаев и Хошимов [2], Азимов [3], Саттаров [4] и Акрамовы [5] в условиях финансово-экономического кризиса посвятили свои научные работы направлению инвестиции в реальный сектор экономики, повышение роли банков в модернизации, техническом и технологическом обновлении предприятий, восстановление экономически несостоятельных предприятий и повышение их финансовой стабильности.

Результаты исследования. Важно поддерживать реальный сектор экономики в решении продолжающегося глобального финансово-экономического кризиса. Этот процесс в Узбекистане продолжается по нескольким направлениям.

Реальный сектор экономики является частью экономики, связанной с производством реальных продуктов и услуг. Валовые доходы несостоятельной несостоятельности ниже валовой себестоимости. Поэтому средства на его реконструкцию не будут короткими, поскольку они неконкурентоспособны из-за высоких издержек производства своей продукции (энергосбережения, цен на сырье и т. Д.) и отрицательной рентабельности предприятия. Теоретически негативными последствиями таких предприятий являются: появление предприятия в ближайшем будущем из определенного сектора экономики; увеличение безработицы; и падение конкуренции в этой области.

Здесь, в развитых странах, мы говорим о процессе финансового оздоровления экономически несостоятельных предприятий.

Практика создания благоприятных условий для заключения соглашения с кредиторами о реорганизации существует и в Англии: так называемый «лондонский подход» предполагает первоначальное получение от Банка Англии гарантий возмещения требований кредиторов на период временного моратория, предшествующего заключению указанного соглашения [6].

Возможно одним из основных препятствий для проведения финансового оздоровления во многих, особенно развивающихся странах, является отсутствие должной поддержки в виде новых финансовых вливаний в предприятия. В США, например, одним из распространенных способов финансирования оздоровления является использование заемного капитала, выдаваемого банками компании, фактически подавшей заявление по Закону о банкротстве. Такое лояльное поведение банков объясняется тем, что все новые кредиты имеют абсолютный приоритет по отношению к долгам предприятия до наступления банкротства. Таким образом, выдавая кредит компании, проходящей процедуру оздоровления, банк во многих случаях имеет высокие шансы погашения ссуды [7].

Особого внимания заслуживает вопрос своевременного предупреждения несостоятельности компаний, что способствует увеличению вероятности сохранения бизнеса. Здесь интересен опыт Франции, где представители суда стремятся инициировать переговоры должника с кредиторами при первых признаках надвигающейся неплатежеспособности. Введение таких превентивных мер обусловлено стремлением не допустить захвата имущества должника, не являющегося пока несостоятельным, со стороны отдельных кредиторов. Что касается должника, для получения судебной защиты ему достаточно просто продемонстрировать наличие финансовых трудностей, способных привести к потере платежеспособности [8].

Банкротство предприятия понимается как юридические действия, которые привели к закрытию некоторого долга без уплаты каких-либо долгов. Финансовая реабилитация предприятия представляет собой комплекс мер, направленных на восстановление производственной деятельности, техническое и технологическое перевооружение предприятия, а также повышение конкурентоспособности продукции, произведенной для того, чтобы спасти предприятие от банкротства.

На следующем рисунке показаны основные направления поддержки реального сектора экономики Республики Узбекистан.

Таким образом, основными направлениями развития реального сектора являются модернизация отрасли, установление прочных отношений между предприятиями и финансовыми институтами и увеличение внутреннего спроса на продукцию, производимую в стране.

Кроме того, реструктуризация задолженности перед другой формой помощи, предоставляемой реальному сектору. Учитывая, что эти долги обусловлены различными причинами, эта политика осуществляется правительством для решения долговой нагрузки, которая влияет на финансовую устойчивость предприятий. 


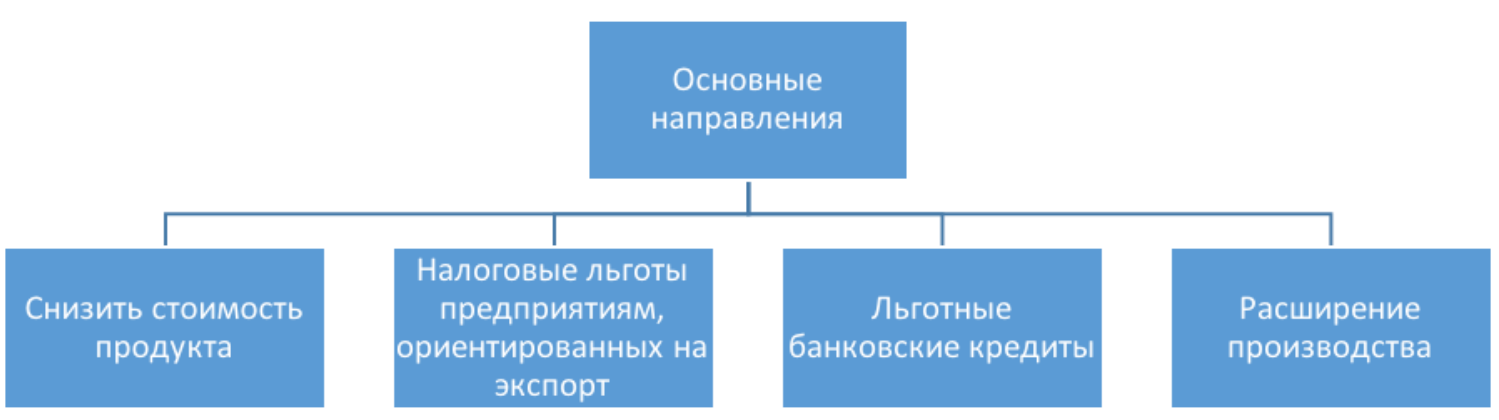

Рис. 1. Основные направления поддержки реального сектора экономики

В то же время, принимая во внимание индивидуальность предприятия, его место в отрасли, финансово-промышленные отношения с другими предприятиями, условия возмещения этих предприятий могут быть установлены по-разному, санкции могут быть отменены или виды долга могут быть удалены с предприятия.

Например, в 2009 году правительство Узбекистана выделило 50 предприятий с государственным бюджетом и государственными фондами для реструктуризации своих текущих долгов для оказания помощи предприятиям реального сектора. В результате этой работы компания инвестировала более 350 миллиардов суммов, потратило более тысячи долларов на предприятия и их модернизацию [9].

Сегодня основным фактором, способствующим успешной реализации глубоких экономических реформ в Узбекистане, является инвестиционная деятельность коммерческих банков. Например, в Узбекистане коммерческие банки становятся все более универсальными в экономике. Немецкие банки активно участвуют в модернизации или общей реабилитации своих предприятий за счет собственных средств, помимо предоставления различных финансовых услуг на протяжении многих лет.

На рисунке 2 представлен масштаб инвестиций коммерческих банков, направленных на модернизацию, техническое и технологическое перевооружение предприятий за счет всех источников финансирования в Республике Узбекистан.

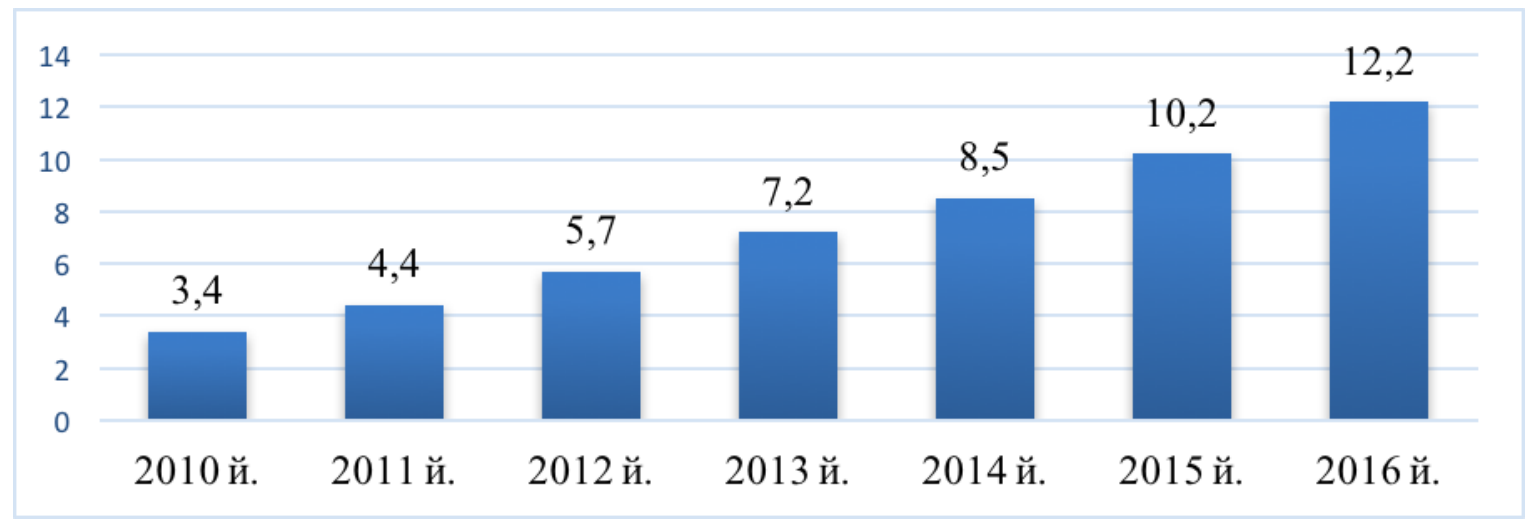

Рис. 2. Динамика инвестиционных кредитов, в трлн суммах

Как видно из рисунка 2, в последние годы эта тенденция неуклонно растет, причем среднегодовые темпы роста в реальном секторе составляют 30 процентов, в среднем 36 процентов и 46 процентов для малых предприятий. За последние пять лет объем инвестиций в экономику банков увеличился в 4,1 раза.

Все банки, ТНК и финансовые учреждения пострадали от последствий глобального финансово-экономического кризиса и стремились смягчить эти последствия за счет долгосрочных национальных экономик.

Был успешно внедрен механизм поиска и продажи инвесторов для обеспечения финансового оздоровления экономически несостоятельных предприятий в балансе коммерческих банков, восстановления производства современных конкурентоспособных продуктов на этих предприятиях, дальнейшего устойчивого развития этих предприятий и финансовой эффективности. В частности, по состоянию на 1 января 2015 года коммерческие банки приняли 173 экономически несостоятельных предприятия на свои балансы (см. Таблицу 1). 
Таблица 1. Экономически несостоятельные предприятия, принятые на балансе коммерческих банков (по состоянию на 1 января 2015 года)

\begin{tabular}{|l|c|c|c|c|}
\hline $\begin{array}{c}\text { Наименование } \\
\text { банков }\end{array}$ & $\begin{array}{c}\text { Количество } \\
\text { принятых }\end{array}$ & $\begin{array}{c}\text { Количество } \\
\text { проданных } \\
\text { инвесторам }\end{array}$ & $\begin{array}{c}\text { Объем инвестиций } \\
\text { банка (в млн. Сум) }\end{array}$ & $\begin{array}{c}\text { Проданные в } \\
\text { процентах }\end{array}$ \\
\hline Национальный банк & 68 & 40 & 253767 & $58,8 \%$ \\
\hline Асака банк & 47 & 46 & 59759 & $97,9 \%$ \\
\hline УзСҚБ & 15 & 13 & 56376 & $86,7 \%$ \\
\hline Агробанк & 14 & 14 & 36221 & $100 \%$ \\
\hline Ипотека банк & 12 & 10 & 26862 & $83,3 \%$ \\
\hline Туран банк & 5 & 5 & 45653 & $100 \%$ \\
\hline Капитал банк & 2 & 1 & 85653 & $50 \%$ \\
\hline Алоқа банк & 3 & 3 & 27844 & $100 \%$ \\
\hline Народный банк & 3 & 3 & 383 & $100 \%$ \\
\hline Инфинбанк & 1 & 1 & 18486 & $100 \%$ \\
\hline Микрокредит банк & 1 & 1 & 48 & $100 \%$ \\
\hline ҚҚБ & 1 & 1 & 2176 & $100 \%$ \\
\hline Хамкор банк & 1 & 1 & 71 & $100 \%$ \\
\hline Жами: & $\mathbf{1 7 3}$ & $\mathbf{1 3 9}$ & $\mathbf{6 1 3 2 9 8}$ & $\mathbf{8 0 , 3 \%}$ \\
\hline
\end{tabular}

Следующие цифры и факты подтверждают, что успешная реализация реформы экономического восстановления экономически несостоятельных предприятий глубоко укоренилась. В таблице 1 показано, что на экономически неплатежеспособных предприятиях коммерческие банки инвестировали 613,3 млрд. долл. США в доходы от мероприятий по модернизации. Центральным банком был введен объем инвестиций в официальный эквивалент 253,2 млн. долларов США. Продукция этих предприятий будет продана с 1 января 2015 года в размере 3115,5 млрд.сумов. и 821,6 млн.сумов из них был экспортирован. По состоянию на 1 января 2014 года эти предприятия создали более 9000 новых рабочих мест в результате мер модернизации. Продажа этих предприятий потенциальным инвесторам, которая была необходима для дальнейших финансовых показателей, находилась на уровне 80,3\%.

Прибыль от продаж 139 медицинских компаний коммерческим банкам превышает 1 трлн. 245,2 млрд. сумов, из них 36,3\%, или 452,2 млрд. сумов, уже были оплачены инвесторами. Средства 44 медицинских предприятий, проданных за 110 млрд. сумов, были полностью оплачены. Еще 953 млрд. сумов долга от продажи 95 других предприятиями, будут регулярно выплачиваться инвесторами. Из этой суммы доля Национального банка составила 596,6 млрд. сумов, или 47,9\% от выручки продаж предприятий.

Разработан механизм стимулирования коммерческих банков по долгосрочным инвестициям в целях финансового оздоровления экономически несостоятельных предприятий в стране. В частности, в структуре кредитного портфеля коммерческих банков применяются налоговые преференции в зависимости от доли долгосрочного инвестиционного финансирования.

Таблица 2.

\begin{tabular}{|c|c|}
\hline $\begin{array}{c}\text { Долгосрочное финансирование } \\
\text { инвестиций в кредитный портфель Банка }\end{array}$ & $\begin{array}{c}\text { Установленная ставка упрощенного } \\
\text { налога на прибыль (в процентах) }\end{array}$ \\
\hline От 35\% до 40\% & $80 \%$ \\
\hline От 40\% до 50\% & $75 \%$ \\
\hline Свыше 50\% & $70 \%$ \\
\hline
\end{tabular}

Кроме того, были приняты следующие меры для облегчения проблем, возникающих при продаже финансовых учреждений:

- продажа предприятий или коммерческих банков в их уставных фондах, а также путем продажи имущества, полученного коммерческими банками по обязательствам должников, и продажи по рыночной стоимости путем прямых переговоров в случае объявления неторговых торгов;

- продажа рыночной стоимости на 10 процентов (но не более 50 процентов от рыночной стоимости), если инвесторы не заинтересованы в результатах прямых переговоров и не заинтересованы в результатах прямых переговоров; 
- все предприятия, продаваемые коммерческими банками, в том числе текстильные предприятия, доли в уставных фондах, обязательства по погашению задолженности и процентные платежи по имуществу, приобретенному должником, без уплаты каких-либо процентов на остаток приобретения, передача имущества и залог третьим лицам.

Теперь проанализируем текущее состояние финансового состояния экономически несостоятельных предприятий, принятых на баланс НБУ.

Столица коммерческих банков и крупные привлекательные депозиты положительно влияют на поддержку банков реальному сектору. Например, на 1 января 2013 года 168 банкам были обеспечены неплатежеспособными предприятиями, которые были предоставлены банками на сумму 388 млрд.сумов. По состоянию на 1 января 2015 года объем инвестиций банков в эти предприятия увеличился на 158\% и составил 613,3 млрд.сумов. Доля предприятий, проданных инвесторам в общем количестве экономически несостоятельных предприятий, возросла с 71,4 процента до 80,3 процента.

В результате на базе обанкротившихся предприятий существует множество производственных возможностей, эти компании разрабатывают конкурентоспособную продукцию с отечественными товарами, и большинство из них ориентированы на экспорт, а государство увеличивает валютные резервы. За последние годы эти предприятия увеличились на 2,8 трлн.сумов, из которых 780 млн.сумов продуктов экспортировались.

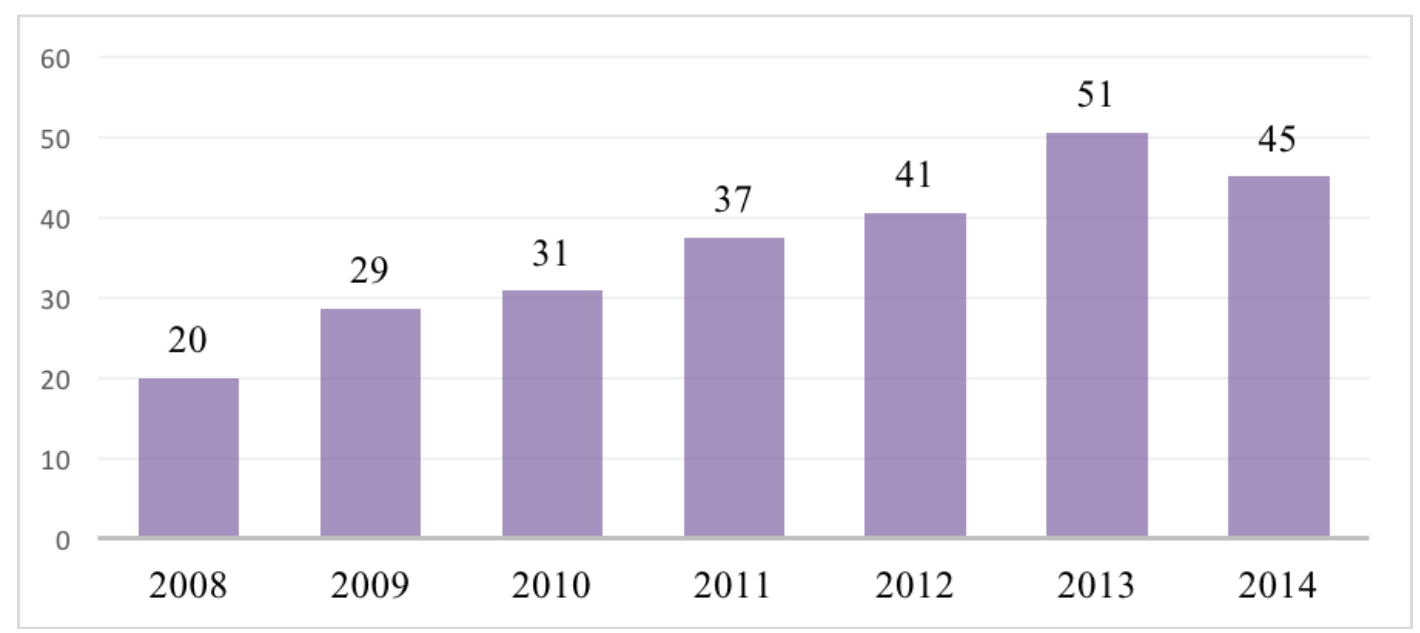

Рис. 3. Объем инвестиций НБУ в экономически несостоятельные предприятия

Рисунок 3 иллюстрирует модернизацию экономически несостоятельных предприятий, а масштаб инвестиций в капитальное строительство имеет устойчивый рост. Общий объем инвестиций составил 244 млрд. сумов, в том числе 129 млрд. сумов была направлена только на модернизацию. Общий объем товаров и услуг, производимых этими предприятиями, составил 852 млрд. сумов. Экспорт продуктов составил 200 миллионов сумов. В 2014 году объем производства составил 286 млрд. сумов и на 67 млн. долл. США был экспорт. На этих предприятиях создано 8431 рабочее место.

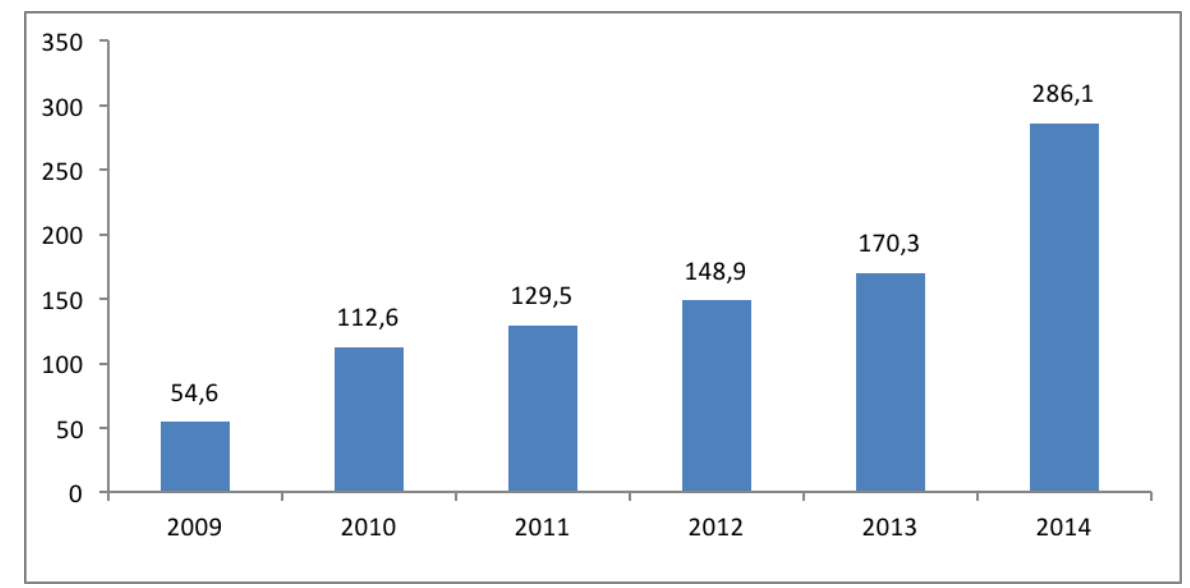

Рис. 4. Объем продукции, производимой экономически несостоятельными предприятиями на балансе НБУ

В результате оперативных мер по продаже финансовых учреждений стратегическим инвесторам общий итог проданных предприятий составило 596 млрд.сумов. По условиям договора 
купли-продажи инвесторы должны были платить по частям. До недавнего времени было оплачено 217 миллиардов сумов, а за 15 предприятий в общем итоге было получено 83 млрд. долларов США. В 2014 году эта цифра превышает сумму по сравнению 2013 годом на 241\%.

Анализ экономически несостоятельных предприятий на балансе НБФО в секторах экономики проиллюстрирован на рисунке ниже.

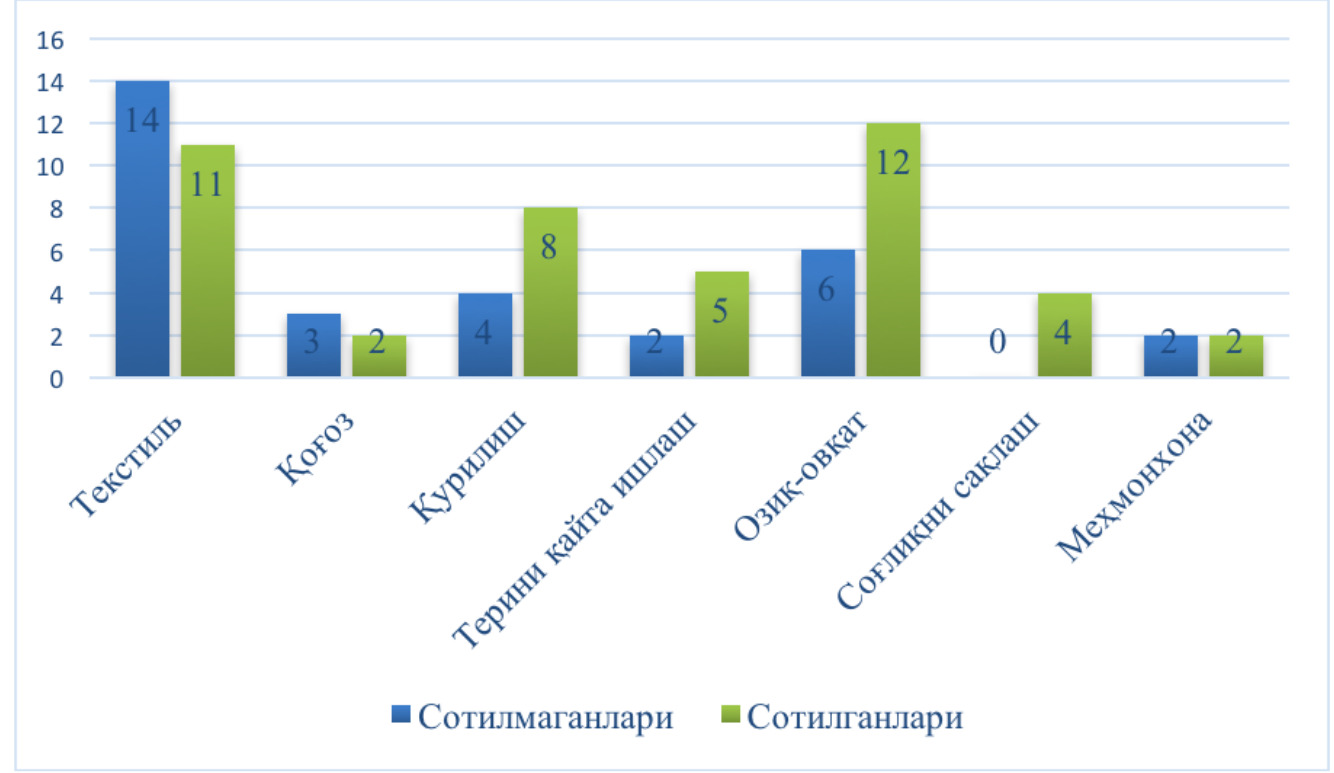

Рис. 5. Экономически несостоятельные предприятия на балансе НБУ в секторах экономики

На рисунке 5 показаны интересные, но отрицательные цифры для текстильной промышленности. Причиной ненадежного характера этих компаний, по моему мнению, является их стоимость, например, около 10 миллиардов долларов и что инвесторы не инвестируют такие большие суммы.

Заключение. Мы разработали следующие практические предложения о том, как продать стратегического инвестора (даже если есть положение) и лучший способ обеспечить финансовую устойчивость вновь созданных дочерних компаний вместо экономически нечувствительных компаний.

- Большинство инвесторов, желающие купить бизнес в банках, - это не иностранные инвесторы, а местные инвесторы. Например, только 25 процентов иностранных инвесторов приобрели в НБУ предприятия.

- Информация о продаже компании была опубликована только в 2000 экземплярах газеты и рекламе на сайтах банков. Это означает, что банки должны работать над маркетингом и рекламой, а также участвовать в международных выставках.

- Прежде чем банк сможет продать предприятие, вам необходимо пройти несколько этапов: погашение банкротских долгов, открытие бизнеса на основе активов, модернизации и производства. Для них инвестиционные компании банка платят большую сумму. В некоторых случаях цена в конце кампании ниже объема инвестиций, сделанных банком. Поэтому банкам желательно продать банк инвестору, который сможет купить на любом этапе всего процесса.

- Одной из основных проблем обеспечения финансовой устойчивости экономически несостоятельных предприятий, успешного производственного процесса и их продажи инвесторам было отсутствие квалифицированного персонала в области корпоративного управления. Успешный персонал в оптимальном управлении активами с низкой или плохими прибылями очень важен для банков. Необходимо организовать учебные курсы в области корпоративного управления и научить их современным методам управления инновациями, определить возможности применения опыта иностранных банков.

- Уровень инфляции в нашей экономике приводит к снижению стоимости реального капитала, который включен в качестве финансового риска. Снижение курса национальной валюты и политика снижения ставки рефинансирования Центрального банка позволят увеличить денежную массу и инвестировать меньше для инвесторов.

- Несмотря на то, что наше правительство придает большое значение строительству дорог и развитию инженерной и коммуникационной инфраструктуры, неадекватная инфраструктура является одной из основных проблем при продаже экономически несостоятельных предприятий, которые были приняты банками. На этот фактор, например, повлияли быстрые продажи экономически 
несостоятельных предприятий в Ташкентской и Ташкентских областях. Развитие инфраструктуры ведет к низкой стоимости производства.

- Информационная асимметрия. В некоторых областях делового сектора бюрократические решения негативно влияют на принятие решений инвесторами.

- Вместе с коммерческими банками Центрального банка мы предлагаем создать совместный веб-сайт с Государственным комитетом по приватизации, демонополизации и развитию конкуренции. С помощью этого веб-сайта все деловые предприятия (проданные и проданные) должны делать то же самое. Этот веб-сайт содержит информацию обо всех товарах. Инвесторы смогут отправлять товары, проданные через этот сайт. Существует также возможность установить ссылки на покупку банков и предприятий на веб-сайте. Недавно открытые предприятия веб-сайта могут сыграть «единое окно» для экономически небезопасных предприятий. Этим обеспечиваются и решаются проблемы, связанные с бизнесом приобретенных предприятий, любые лицензии, проблемы со связью, связанные с подключением, заявки на предоставление кредитов и любые другие проблемы, могут ускорить всю работу, которая может быть решена в Интернете через этот сайт и объективно решить их без бюрократических барьеров.

\section{ЛИТЕРАТУРА}

1. Файншмидт, Е. А. Международная практика антикризисного управления [Текст]: учебник. Ч.2. / Файншмидт Е. А. - М.: Издательско-торговая корпорация «МК», 2006.-400 с.

2. Thonabauer and Nosslinger. Credit approval process and Credit Risk Management. Vienna: Oesterreichische National Bank, p. 45. 2004https://www.oenb.at/en/Publications/FinancialMarket/Publications-of-Banking-Supervision/archive-guidelines-and-publications.html

3. Martini et. al. "Bad banks finding the right exit from the financial crisis". Several bad bank concepts being discussed internationally, McKinsey and Company. P. 13. 2009

4. Barton C., Wilson R. "Conventional loan workouts". Conventional loan work workouts, Dallas: Texas. P.6. 2010

5. Flechtner A. "REFIRE and Crown Credit Services GmbH Interview: Primary and special servicing". 2012

6. Мелехова, Т. В. (2012). Практика финансового оздоровления предприятий в России и за рубежом. НаучныезапискиОрелГИЭТ, (2), 214-218.

7. Jahn N., Memmel C., Pfingsten A. "Discussion paper: Bank's concentration versus diversification in the loan portfolio: new evidence from Germany”. Bndespank discussion paper, \#53, 2013, P. 29. http://www.sefifrance.fr/images/documents/mckinsey_a_risk_management_approach_to_a_successful_infr astructure project.pdf

8. Вахабов А., Жумаев Н., Хошимов Е. Глобальный финансовый кризис: причины, особенности и пути смягчение экономики. Ташкент, Академия, 2009.

9. Cavalier, G. A. (2008). French Bankruptcy Law and Enforcement Procedures: Commercial Code-Article L. 632-2 para. 2.Азимов 3. Иқтисодий ночор корхоналарни соғломлаштиришда банкларнинг роли. Бозор, пул, кредит. 2013, №4. 5-7 б.

10. Саттаров Б. Инвестиционная деятельность банков - развитие экономически несостоятельных предприятий. Рынок, деньги, кредит. 2013, №10. 56-59 стр.

11. Акрамов Б. На пути оздоровления экономически-несостоятельных предприятий. Рынок, деньги, кредит. 2013 №10. 28 стр.

12. Каримов И. А. «Глобальный финансово-экономический кризис, пути и меры по его преодолению в условиях Узбекистана». Ташкент, Узбекистан, 2009. 6 стр.

13. Barton C., Wilson R. "Conventional loan workouts". Conventional loan work workouts, Dallas: Texas. P.6. 2010

14. Flechtner A. "REFIRE and Crown Credit Services GmbH Interview: Primary and special servicing". 2012

15. Jahn N., Memmel C., Pfingsten A. "Discussion paper: Bank's concentration versus diversification in the loan portfolio: new evidence from Germany". Bndespank discussion paper, \#53, 2013, P. 29.

16. Martini et. al. "Bad banks finding the right exit from the financial crisis". Several bad bank concepts being discussed internationally, McKinsey and Company. P. 13. 2009

17. Thonabauer and Nosslinger. Credit approval process and Credit Risk Management. Vienna: Oesterreichische National Bank, p. 45. 2004.

18. Хайдаров А. Я. Презентация «Банковские и финансовые институты в модернизации реального сектора экономики Республики Узбекистан» на Республиканской научно-практической конференции, организованной Академией банковского дела и финансов Республики Узбекистан 19 ноября 2014 года.

19. http://www.doingbusiness.org/reports/global-reports/ /media/WBG/DoingBusiness/Documents/AnnualReports/English/DB12-Chapters/Resolving-Insolvency.pdf

20. http://www.uncitral.org/pdf/english/workinggroups/wg_5/51stWG5/MSMEs_Rehabilitation_Proceedings_ Korea_20170505.pdf

21. http://www.iflr.com/Article/3712325/2017-Insolvency-and-Corporate-Reorganisation-Report-Japan.html

22. http://orelgiet.ru/docs/nauchzap/44-melehova.pdf

23. https://lomonosov-msu.ru/archive/Lomonosov_2007/08/gililovmark@inbox.pdf 